\title{
New Diagnostic and Predisposing Parameters for Acute Acalculous Cholecystitis
}

\author{
M. OZTAS AND Y. S. PEKER* \\ Department of General Surgery, Gulhane Training and Research Hospital, University of Health Sciences, 06010, Ankara, \\ Turkey
}

Oztas and Peker et al.: Acute acalculous cholecystitis treatment

\begin{abstract}
The purpose of this study is to examine the prevalence and diagnostic criteria of acute acalculous cholecystitis patients at Gulhane Training and Research Hospital and investigate etiopathogenesis and treatment outcomes. Filed data of all patients treated at the clinic for acute cholecystitis during 2016-2019 was analyzed. The demographic and clinicopathologic characteristics, diagnostic and operative parameters and gallbladder histopathology findings of the patients were examined. The patients diagnosed with acute calculous cholecystitis and acute acalculous cholecystitis was compared as 2 groups. Nine (4.6\%) of the 197 patients were diagnosed with acute cholecystitis and the rest with acute acalculous cholecystitis. The mean ages of the acute acalculous cholecystitis and acute calculous cholecystitis groups were 64.9 and 57.3 $y$, respectively. No predisposing factors could be found in any acute acalculous cholecystitis patient. While there was no significant difference between both the groups in terms of age, alanine aminotransferase, aspartate aminotransferase, white blood cell count, gallbladder distension, gallbladder wall thickness, and hospitalization duration, a significant difference was found in the acute acalculous cholecystitis group's pericholecystic fluid and C-reactive protein levels. Consequently, even if there are no predisposing factors, clinicians should keep in mind that acute acalculous cholecystitis may be observed especially in patients aged 60 y or above with presence of pericholecystic fluid and high C-reactive protein levels. In these patients, if they are surgically suitable, early cholecystectomy would have positive prognosis.
\end{abstract}

Key words: Acute acalculous cholecystitis, cholecystectomy, pericholecystic fluid

The possibility of occurrence of acute acalculous cholecystitis (AAC) in the gallbladder was firstly defined in 1844, which is accepted that this pathological condition may be usually seen in the presence of some predisposing factors ${ }^{[1]}$. It is known that AAC is frequently prone to complications such as gallbladder gangrene and perforation and has poor prognosis if it is not treated early. Delayed diagnosis and treatment in AAC cases that are hospitalized for different serious medical conditions that do not show classical acute cholecystitits (AC) symptoms lead to the emergence of severe complications and high rates of mortality. As medical treatment by itself is usually not successful in treatment of AAC, application of early cholecystectomy or percutaneous cholecystostomy is recommended as treatment and cholecystectomy may be a challenging operation for the surgeon (fig. 1) ${ }^{[2]}$.

While it is accepted that AAC is usually seen in cases of cardiovascular surgery, abdominal surgery, severe trauma, severe burns, long-term hunger, long-term total parenteral nutrition (TPN) application or sepsis, there are a few studies in the literature showing that AAC may develop without these predisposing factors. Among AC cases, AAC has a rate of 1-15\% (Table 1) ${ }^{[1-10]}$. There are also several really rare infections that cause AAC (Table 2) ${ }^{[11-22]}$. However, the incidence of AAC in children is much more than the in adults with 50 to $70 \%{ }^{[5,23]}$. This is especially because of the childhood viral infections and also it is relatively high due to low rate of ACC in childhood ${ }^{[5,24]}$.

Diagnosis of AAC is a topic of debate also. There is no standardization for the diagnosis of AAC except patient having acute cholecystitis without gallstones and predicting this situation preoperatively is the main problem for diagnosis of ACC ${ }^{[25]}$. Ultrasonography is the gold standard for diagnosis of $\mathrm{AC}$ but has limitations for the diagnosis of $\mathrm{AAC}^{[26]}$. There is no $\mathrm{AAC}$ specific laboratory finding for AAC, which also makes the diagnosis more difficult for the clinicians ${ }^{[27]}$. The laboratory findings of AAC may be similar to laboratory findings of AC. The purpose of this study is to examine the prevalence and diagnostic criteria of 
AAC patients at the Gulhane Training and Research Hospital to assess its etiopathogenesis, clinical course and outcomes by comparing ACC cases.

One hundred and ninety-seven patients who received treatment at the Gulhane Training and Research Hospital due to AC in the period of 2016-2019 were retrospectively examined. The AC cases that satisfied all of the following criteria were accepted as AAC. No gallstone at radiological imaging such as ultrasonography or computerized tomography despite having clinical AC findings, operative findings compatible with $\mathrm{AC}$ and observing that there is no gallstone. Histopathological confirmation of gallbladder inflammatory findings. The demographical, clinical, laboratory and radiologic findings of 9 AAC patients with these criteria were evaluated and compared with ACC patients.

The results obtained were compared to the data of 188 ACC patients. For the data consisting of 2 independent groups and having a normal distribution, MannWhitney U test was applied by using SPSS v25 and $\mathrm{p}<0.05$ was accepted as statistically significance.

Within the $3 \mathrm{y}$ period of the study, 197 patients hospitalised with the diagnosis of $\mathrm{AC}$ at Gulhane Training and Research Hospital were treated. Among these, 9 AAC patients were determined. The male/ female ratio of the group with AAC diagnosis was 5/4, while their mean age was 64.6 y (27- 83 y, Table 3$)$.

Except for hypertension and complication-free diabetes mellitus, no disease that would cause predisposition

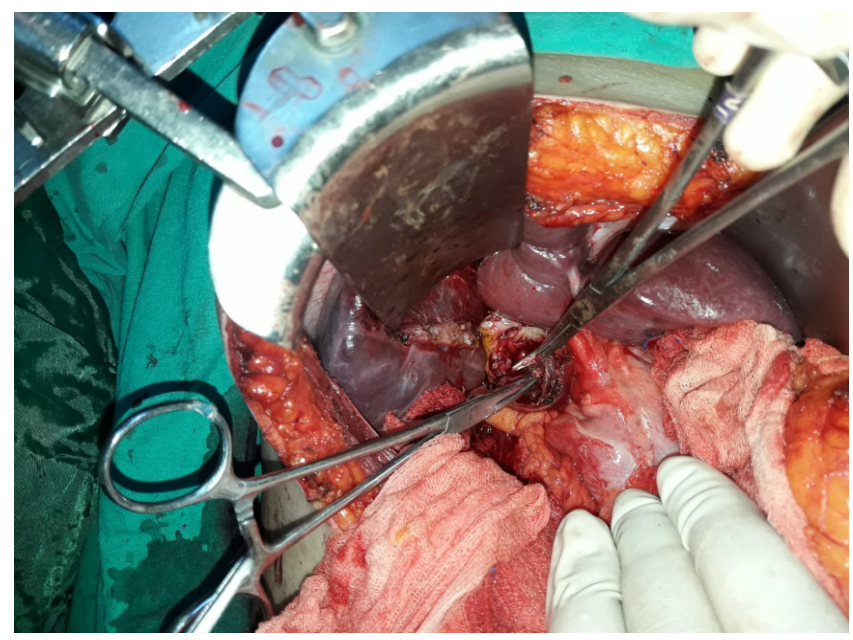

Fig. 1: Partial cholecystectomy

Early cholecystectomy may be a challenging operation for the surgeon that even the surgeon may apply partial cholecystectomy due to not to injure ductal and vascular structures of liver. In the figure partial cholecystectomy is seen which remnant gallbladder is left back and sewn right after

Special Issue 5, 2020
TABLE 1: ETHIOLOGIES OF ACUTE ACALCULOUS CHOLECYSTITIS

\begin{tabular}{c}
\hline ETHIOLOGY OF AAC \\
Cardiovascular Surgery \\
Abdominal Surgery \\
Severe Trauma \\
Severe Burns \\
Long-Term Hunger \\
Long-Term TPN Application \\
Sepsis \\
DM \\
Malignant disease \\
Abdominal vasculitis \\
Congestive heart failure \\
Cholesterol embolization \\
Shock \\
Cardiac arrest \\
Prolonged fasting \\
Elderly patients \\
Idiopathic
\end{tabular}

$\overline{\text { AAC }}$ is acute acalculous cholecystitis, TPN is total parenteral nutrition, DM is diabetes mellitus

TABLE 2: RARE ENFECTIOUS ETHIOLOGIES OF AAC

\begin{tabular}{c}
\hline Enfectious Ethiology of AAC \\
\hline Salmonellosis \\
Fusarium species \\
Brucellosis \\
Giardia lamblia \\
Toxocarosis \\
Zika virus \\
EBV \\
HAV \\
HBV \\
HCV \\
Leptospirosis \\
Plasmodium Falciparum
\end{tabular}

$\overline{A A C}$ is acute acalculous cholecystitis, EBV is Ebstain Barr Virus, HAV is Hepatitis A Virus, HCV is Hepatitis C Virus

for AAC could be found among the patients. The most frequent symptom of the patients was upperright quadrant pain, and cholangitis findings were not observed in any AAC patients. Fever was determined at the time of admission among 3 patients due to AAC. In difference to the initial symptoms of AAC patients, it was determined that the patients who visited the clinic with ACC were admitted with several different symptoms including nausea, vomiting, and radiological findings of cholangitis.

All patients who were admitted to the clinic with AAC were treated by cholecystectomy after medical antibiotic and analgesic treatment. One patient received 
TABLE 3: DEMOGRAPHICAL, LABORATORY, RADIOLOGICAL AND CLINICAL FINDINGS OF AAC AND ACC PATIENTS. STATISTICALLY SIGNIFICANT DIFERENCE HAS BEEN FOUND BETWEEN CRP LEVELS AND PERICHOLECYSTIC FLUID PRESENCE

\begin{tabular}{lccc}
\hline Results (mean) & AAC & ACC & p value \\
\hline Age (y) & 64.6 & 57.3 & 0.128 \\
WBC (x1000/mm3) & 15.2 & 14.3 & 0.590 \\
CRP (mg/L) & 234.3 & $119.5 \mathrm{~F}$ & 0.026 \\
ALT (IU/L) & 292.2 & 56.4 & 0.653 \\
AST (IU/L) & 324.5 & 46.1 & 0.254 \\
Gallbladder wall thickness & 6.81 & 5.54 & 0.072 \\
(mm) & $77.8 \%$ & $47.8 \%$ & 0.015 \\
Pericholecystic fluid presence & & & \\
Gallbladder distension & $88.8 \%$ & $69.1 \%$ & 0.208 \\
presence & 9.1 & 7.7 & 0.156 \\
\hline Hospitalisation duration (d) &
\end{tabular}

AAC is acute acalculous cholecystitis, ACC is acute calculous colecystitis, WBC is white blood cell, CRP is C-reactive protein, ALT is alanine aminotransferase, AST is aspartate aminotransferase

conventional cholecystectomy, 8 patients received laparoscopic cholecystectomy and no postoperative complications were observed. On the other hand, in the ACC group, different treatment alternatives such as endoscopic retrograde cholangiopancreatography (ERCP) and percutaneous cholecystostomy were also applied. The white blood cell (WBC), C-reactive protein (CRP), alanine aminotransferase (ALT) and aspartate aminotransferase (AST) levels, age, gallbladder distension, gallbladder wall thickness, presence of pericholecystic fluid and hospitalization durations of the $\mathrm{AAC}$ and $\mathrm{ACC}$ patients were compared. No significant difference could be determined between the two groups except for their CRP levels and pericholecystic fluid collection $(p=0.026, p=0.015$, Table 3$)$.

$\mathrm{AAC}$ is a rare gallbladder infection that develops without gallstone but has a severe course. Infection in AAC cases is more progressive in comparison to ACC cases, and complications such as gangrene or perforations are seen in $10 \%$ of cases $^{[1,28,29]}$. While AAC cases are usually seen in and older the sixth decade of life and frequently in men, ACC cases are usually seen in the fourth and fifth decades and frequently in women ${ }^{[3,30]}$. The results of this study supported this information published in literature (Table 3).

The onset of infection in the gallbladder and the inflammation process are classically explained by cholestasis developing in relation to obstruction of the cystic duct by gallbladder stone and physiological events that occur later. However, the cause and development of inflammation in AAC are under debate. For this reason intraoperative cholangiography may also be applied (fig. 2). The physiopathology of AAC has been aimed to be explained by contraction dysfunction of the gallbladder due to ischemia or other reasons resulting cholestasis, bacterial colonization, increase of intraluminal pressure and potential gangrene/ necrosis development in the gallbladder due to severe inflammation. The AAC development mechanism in the gallbladder has been also experimentally demonstrated with ischemia-reperfusion injury studies. The most frequent colonization occurs by enteric bacteria such as Escherichia coli, Klebsiella, Bacteroides, Proteus, Pseudomonas and Enterococcus faecali ${ }^{[1,2,31]}$.

Infection in AAC cases tends to progress very rapidly, and thus, the disease may result in complications

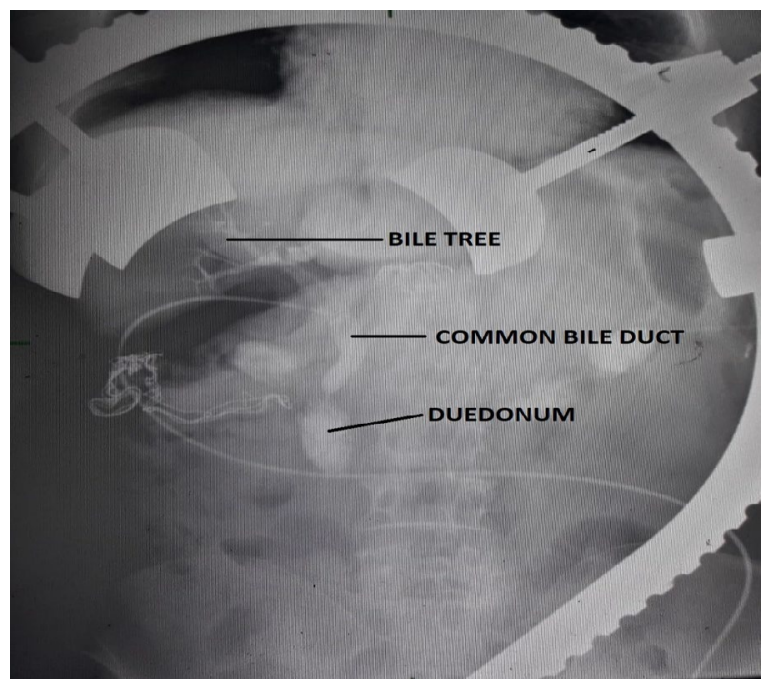

Fig. 2: Intraoperative cholangiography

One of the ways to diagnose calculous and acalculous cholecystitis is intraoperative cholangiography due to detect the gall stones located at common bile duct and also to make sure that there is no injury to the common bile duct after an challenging operation

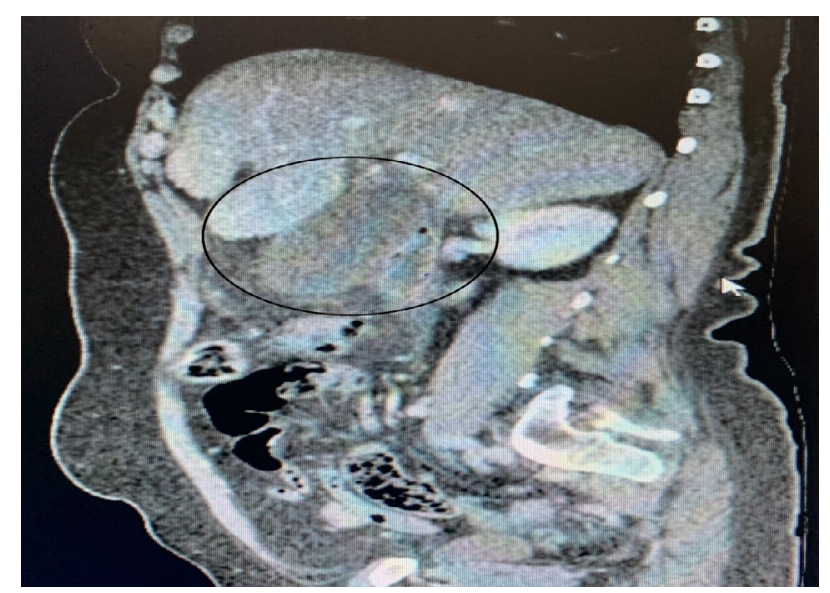

Fig. 3: Computarized tomographic image of acute cholecystitis

Distension of gall bladder due to acalculous cholecystitis is seen in the computerized tomography with increased wall thickness 
in the gallbladder such as gangrene, perforation and sepsis ${ }^{[32,33]}$. If treatment is delayed, the clinical picture becomes more severe by the emergence of complications. After these complications, a catastrophic clinical presentation such as sepsis and multiorgan dysfunction develops, and it may result with death. The reason for this is because of lack of immunity of the patient due to underlying predisposing factors as severe disease, and delayed diagnosis in most cases. Underlying predisposing disease masking the clinical presentation and laboratory findings of $\mathrm{AC}$ in addition to failure to diagnose cholecystitis with ultrasound lead to misdiagnosis of AAC. In most published series, it is seen that the AAC patients are those that have advanced age and deteriorated general status who are hospitalized due to other medical problems ${ }^{[1,34,35]}$. As in many infections, the treatment method is intravenous antibiotics and application of cholecystectomy for resource management or percutaneous cholecystostomy in high-risk AAC patients. Although some researchers have recommended preference of cholecystostomy in AAC treatment for patients with deteriorated general status and elderly patients ${ }^{[36-39]}$, laparoscopic cholecystectomy is the gold standard method at many experienced centres ${ }^{[34,40-42]}$. But still, Treinen et al. approach may be the most appropriate approach for all the centres including experienced and not-experienced one ${ }^{[43]}$. According to his review, he suggests three-prolonged approach which includes laparoscopic cholecystectomy, open cholecystectomy and cholecystostomy. He suggests deciding according to patients critically ill situation, comorbidities, conversion risk, and on to his suggestions, we add the centres experience.

In the present study, as there was no predisposing factor at the patients and the mean age of the patients was younger than expected, there was no delayed diagnosis, and the treatment was applied early which the treatment protocol was, patients were treated with initial intravenous antibiotics treatment and early cholecystectomy, while no patient was treated by percutaneous cholecystostomy or ERCP. As a result, no complications such as gallbladder gangrene or perforation were seen in the patients, and percutaneous cholecystostomy was not needed.

The progression of AAC is very rapid that it may lead to death in a short time and early intervention is important as mentioned above. However, postoperative patient care is also important for the AAC patients. Laurila et al. studied the organ system dysfunction fallowing open cholecystectomy in 24 patients $^{[44]}$. They found out that the median Sequential Organ Failure Assessment (SOFA) score $3 \mathrm{~d}$ before the cholecystectomy in AAC patients was 7.5 and increased to 10.5 on the day of cholecystectomy postoperatively which the score indicates the multiorgan dysfunction. The difference between the two scores were statistically significant $(p<0.0001)$. The SOFA score on postoperative day 7 was decreased to 5.5. These results showed the importance of surgical intervention of AAC but also emphasize the importance of postoperative patient care for AAC patients. It should be kept in mind that low quality patient care for AAC patients may lead to death of even if an excellent surgical intervention is applied to patient.

The reason why no mortality and morbidity was observed in this study might be because of the patient group had no AAC patients with classical etiologies. However as mentioned above, the AC patients were candidates of multiple organ dysfunction so every AAC patient operated for cholecystectomy should be postoperatively fallowed up by intensive care unit with appropriate wide spectrum antibiotherapy even if the patient doesn't have any classical predisposant factors for AAC.

The most prevalent biochemical anomaly in AAC patients in addition to increased WBC and CRP values is the excessively high levels of ALT and AST. In this study, there was no significant difference between the two groups regarding these laboratory tests, only the difference in the CRP levels was statistically significant $(\mathrm{p}=0.026$, Table 3$)$. No significant difference between ALT and AST levels between the 2 groups might be a result of patients not having severe comorbidities as usual AAC patients. The pathological values of these enzymes are usually seen in ACC cases and as a result of obstruction of the common bile duct with gallbladder stone ${ }^{[2,45,46]}$. On the other hand, this study showed that much higher CRP values than ACC patients at the stage of diagnosis in AAC patients are more significant than high WBC values in the diagnosis (Table 3 ).

With the progression of the infection and tissue damage in the gallbladder, thickening in the gallbladder wall, gallbladder distension (Hydrops vesicalis) and pericholecystic fluid collection occur. As seen in Table 3 , while there is difference between two groups in terms of the gallbladder wall thickness, distension and pericholecystic fluid collection, the pericholecystic fluid collection was statistically significant $(\mathrm{p}=0.015)$. In a low number of suspicious cases that cannot be diagnosed 
by ultrasonography, cholescintigraphy with a HIDACCK combination and computerized tomography may help the diagnosis ${ }^{[4]}$ (fig. 3). However, it should not be forgotten that ultrasonography is the gold standard for diagnosis of AC. For this reason, clinicians should keep the diagnosis of AAC in mind for the patients with pericholecystic fluid collection who are aged $60 \mathrm{y}$ or above and has no predisposing comorbidities for AAC.

As discussed above, the most important predisposing factors for AAC are cardiovascular surgery, abdominal surgery, severe trauma, severe burns, long-term hunger, long-term TPN application or sepsis however hypertension and controlled diabetes mellitus (DM) is not assumed as predisposing factor for AAC cases $^{[1-11,48]}$. However, in this study it was found out that the only probable predisposing factor for AAC cases may not be the ones listed above but also hypertension and controlled DM may be considered as predisposing factors for AAC as them also being chronic disease.

One of the rare studies that supported these recommendation for accepting HT and controlled DM as predisposant factor for AAC is by Croley ${ }^{[49]}$. The author studied 126 gangrenous cholecystitis patients and found out $5 \mathrm{AAC}$ patients with non-perforated ileus patients. The evaluation of the patients resulted with 2 AAC patients representing as gangrenous cholecystitis. Interestingly, he found out that 5 patients had HT and DM comorbidities in common. Although at the conclusion part of his study, he emphasized more on the relation between ileus and gangrenous cholecystitis, the two patients having HT and DM as and representing as AAC patients may be a lately noticed result of his study. He also concludes the importance of early operation.

Valdivia-Gomez et al. also drew the attention of clinicians to evaluate HT and DM as predisposant factors for AAC especially for non-hospitalized patients $^{[50]}$. In their article, they studied 810 out-patients and found $27 \mathrm{AAC}$ patients with mean age of $37 \mathrm{y}$ which is significantly younger than our results. He found out that $12(44 \%)$ of the AAC patients were related with HT and DM. They concluded the importance of keeping in mind that AAC is not always related with critically ill patients and elder patients which endorses our study's results. They also suggested immediate cholecystectomy for AAC patients.

As conclusion, in all patients with cholecystitis symptoms, laboratory and radiologic findings and increased infection markers such as WBC and CRP, although gallstone cannot be imaged in ultrasonography, medical treatment for acute cholecystitis should be started without delay, and the diagnosis should be clarified by advanced radiological and biochemical examinations in a short time. Especially in patients in whom in and older than sixth decade, pericholecystic fluid is detected, the CRP levels are higher than expected, and gallstone is not detected, the diagnosis of AAC should be definitely considered, and early cholecystectomy should be planned for a better course of the prognosis. Even if there are no predisposing factors for AAC in these patients, AAC should not be excluded, and additionally, it should be kept in mind that even if there is no classical literature information, uncontrolled diabetes and hypertension may also be etiological factors.

\section{Conflict of interest:}

All authors report no conflicts of interest in this work.

\section{REFERENCES}

1. Jones MW, Ferguson T. Acalculous cholecystitis. StatPearls. StatPearls Publishing, 2020.

2. Bryan B. Recent advances in management of acalculous cholecystitis. F1000Research 2018;7.

3. Ganpathi IS, Diddapur RK, Eugene H, Karim M. Acute acalculous cholecystitis: challenging the myths. HPB 2007;9:131-4.

4. Barie PS, Eachempati SR. Acute acalculous cholecystitis. Gastroenterol Clin North Am 2010;39:343-57.

5. Poddighe D, Sazonov V. Acute acalculous cholecystitis in children. World J Gastroenterol 2018;24:4870-79.

6. Huffman JL, Schenker S. Acute acalculous cholecystitis: A Review. Clin Gastroenterol Hepatol 2010;8:15-22.

7. Kalliafas S, Ziegler DW, Flancbaum L, Choban PS. Acute acalculous cholecystitis: incidence, risk factors, diagnosis, and outcome. Am Surg 1998;64:471-5.

8. Doran H, Mihalache O, Bobirca FI, Buga C, Patrascu T. acute acalculous cholecystitis-difficulties of diagnosis and treatment. Chirurgia Bucur 2010;105:465-8.

9. Liu FL, Li H, Wang XF, Shen KT, Shen ZB, Sun YH, et al. Acute acalculous cholecystitis immediately after gastric operation: case report and literatures review. World J Gastroenterol 2014;20:10642-50.

10. Szvalb AD, Kontoyiannis DP. Acute acalculous cholecystitis due to Fusarium species and review of the literature on fungal cholecystitis. Mycoses 2019;62:847-53.

11. Lianos GD, Drosou P, Souvatzoglou R, Karampa A, Vangelis G, Angelakis E, et al. Acute Acalculous Cholecystitis with Empyema due to Salmonellosis. Case Rep Gastrointest Med 2019:5185314.

12. Szvalb AD, Kontoyiannis DP. Acute acalculous cholecystitis due to Fusarium species and review of the literature on fungal cholecystitis. Mycoses 2019;62:847-53.

13. Hariz A, Beji I, Hamdi MS, Cherif E. Brucellosis, an uncommon cause of acute acalculous cholecystitis: two new cases and concise review. BMJ Case Rep 2019;12:e229616. 
14. Araki H, Shimizu S, Hayashi K, Yamada T, Kusakabe A, Kanie $\mathrm{H}$, et al. Acute acalculous cholecystitis caused by giardia lamblia. Intern Med 2017;56:1657-1662.

15. Strickler A, Vasquez N, Maggi L, Hernandez J, Hidalgo X. toxocarosis and acalculous acute cholecystitis: consequence or coincidence? Rev Chilena Infectol 2016;33:346-51

16. Ono SK, Bassit L, Van Vaisberg V, Avancini Ferreira Alves V, Caldini EG, Herman BD, et al. Acute acalculous cholecystitis during zika virus infection in an immunocompromised patient. Hepatology 2018;67:2051-4.

17. Chalupa P, Kaspar M, Holub M. Acute acalculous cholecystitis with pericholecystitis in a patient with Epstein-Barr Virus infectious mononucleosis. Med Sci Monit 2009;15:CS30-3.

18. Cuk P, Iqbal M, Lykke J. Perforated acute acalculous cholecystitis caused by hepatitis A. Ugeskr Laeger 2014; 176:V12130701.

19. Castelijn DAR, Wattel-Louis GH. An acute acalculous cholecystitis in a returned travel couple. PLoS Negl Trop Dis 2018; 12:e0006177.

20. Wright WF, Palisoc K, Pinto CN, Lease JA, Baghli S. Hepatitis $\mathrm{C}$ virus-associated acalculous cholecystitis and review of the literature. Clin Med Res 2020;18:33-6.

21. Mohammed RA, Ghadban W, Mohammed O. Acute acalculous cholecystitis induced by acute hepatitis B virus infection. Case Reports Hepatol 2012;2012:132345.

22. Aguilera-Alonso D, Lopez Medina EM, Del Rosal T, Villota Arrieta J, Escosa-Garcia L, García-Hortelano. Acalculous cholecystitis in a pediatric patient with plasmodium falciparum 1nfection: a case report and literature review. Pediatr Infect Dis J 2018;37:e43-5.

23. Simões AS, Marinhas A, Coelho P, Ferreira S. Acalculous acute cholecystitis during the course of an enteroviral infection. BMJ Case Rep 2019;12:e228306.

24. Pampaloni F, Noccioli B, Mattei R, Pampaloni A. primary acute acalculous cholecystitis in childhood: a report of 2 clinical cases. Pediatr Med Chir 1997;19:205-210.

25. Huffman JL, Schenker S. Acute acalculous cholecystitis: a review. Clin Gastroenterol Hepatol 2010;8:15-22.

26. Thampy R, Khan A, Zaki IH, Wei W, Korivi BR, Staerkel G. Acute acalculous cholecystitis in hospitalized patients with hematologic malignancies and prognostic importance of gallbladder ultrasound findings. J Ultrasound Med 2019;38:5161.

27. Trowbridge RL, Rutkowski NK, Shojania KG. Does this patient have acute cholecystitis? JAMA 2003;289:80-6.

28. Pomata M, Pisano G. Primary acute acalculous cholecystitis. G Chir 1995;16:43-47.

29. Eriksen K, Reinstrup P. Acute acalculous cholecystitis. Ugeskr Laeger 1994;156:3311-4.

30. Gu MG, Kim TN, Song J, Nam YJ, Lee JY, Park JS. Risk factors and therapeutic outcomes of acute acalculous cholecystitis. Digestion 2014;90:75-80.

31. Taoka H. Experimental study on the pathogenesis of acute acalculous cholecystitis with special reference to the roles of microcirculation disturbances, free radicals and membrane bound phospolipase A2. Gastroenterol Jpn 1991;26:633-44.

32. Johnson LB. The Importance of Early Diagnosis of Acute Acalculus Cholecystitis. Surg Gynecol Obstet 1987;164:197203.

33. Hill AG, Collins JP. Acute acalculous cholecystitis. Aust N Z J Surg 1994;64:251-3.

34. Schuld J, Glanemann M. Acute cholecystitis. Viszeralmedizin 2015;31:163-5.
35. Chung SC. Acute acalculous cholecystitis. Postgrad Med 1995;98:199-204.

36. Simorov A, Ranade A, Parcells J, Shostrom ASV, Boilesen E, Goede M, et al. Emergent cholecystostomy is superior to open cholecystectomy in extremely 1 ll patients with acalculous cholecystitis: a large multicenter outcome study. Am J Surg 2013;206:935-41.

37. Kirkegård J, Horn T, Christensen SD, Larsen LP, Knudsen AR, Mortensen FV. Percutaneous cholecystostomy is an effective definitive treatment option for acute acalculous cholecystitis. Scand J Surg 2015;104:238-43.

38. Griniatsos J, Petrou A, Pappas P, Revenas K, Karavokyros I, Michail OP, et al. Percutaneous cholecystostomy without interval cholecystectomy as definitive treatment of acute cholecystitis in elderly and critically ill patients. South Med J 2008;101:586-90.

39. Noh SY, Gwon DI, Ko GY, Yoon HK, Sung KB. Role of percutaneous cholecystostomy for acute acalculous cholecystitis: clinical outcomes of 271 patients. Eur Radiol 2018;28:1449-55.

40. Barie PS, Eachempati SR. Acute acalculous cholecystitis. Gastroenterol Clin North Am 2010;39:343-57.

41. Soria Aledo V, Galindo Iniguez L, Flores Funes D, Carrasco Prats M, Aguayo Albasini JL. Is cholecystectomy the treatment of choice for acute acalculous cholecystitis? A systematic review of the literature. Rev Esp Enferm Dig 2017;109:70818.

42. Ueno D, Nakashima H, Higashida M, Yoshida K, Hino K, Irei I, et al. Emergent laparoscopic cholecystectomy for acute acalculous cholecystitis revisited. Surg Today 2016;46:309-12.

43. Treinen C, Lomelin D, Krause C, Goede M, Oleynikov D. Acute acalculous cholecystitis in the critically 1ll: risk factors and surgical strategies. Langenbecks Arch Surg 2015;400:4217.

44. Laurila PA, Saarnio J, Koivukangas V, Syrjala H, Ala-Kokko TI. Organ system dysfunction following open cholecystectomy for acute acalculous cholecystitis in critically 11 patients. Acta Anaesthesiol Scand 2006;50:173-9.

45. Dogra R. Acute acalcoulous cholecystitis. Med J Armed Forces India 1995;51:294.

46. Huffman JL, Schenker S. Acute acalculous cholecystitis: a review. Clin Gastroenterol Hepatol 2010;8:15-22.

47. Shapiro MJ, Luchtefeld WB, Kurzweil S, Kaminski DL, Durham RM, Mazuski JE. acute acalculous cholecystitis in the critically 1ll. Am Surg 1994;60:335-9.

48. McChesney JA, Northup PG, Bickston SJ. Acute acalculous cholecystitis associated with systemic sepsis and visceral arterial hypoperfusion: a case series and review of pathophysiology. Dig Dis Sci 2003;48:1960-7.

49. Croley GG. Gangrenous cholecystitis: Five patients with intestinal obstruction. Am Surg 1992;58:284-92.

50. Valdivia-Gomez GG, Suarez R, Chavelas-Lluck MA, CanedaMejia M, Zaga-Minian I. Acute non-calculous cholecystitis in non-hospitalized patients. Gac Med Mex 1995;131:405-8.

This is an open access article distributed under the terms of the Creative Commons Attribution-NonCommercial-ShareAlike 3.0 License, which allows others to remix, tweak, and build upon the work non-commercially, as long as the author is credited and the new creations are licensed under the identical terms

This article was originally published in a special is-
sue, "Biomedical Research in Healthcare Setting"
Indian J Pharm Sci 2020:82(2)Spl issue5;16-21

